\title{
FRIDA KAHLO, À REVOLUÇÃO: O USO DA FOTOETNOGRAFIA COMO NARRATIVA EMOTIVA NA PEÇA TEATRAL
}

\author{
Robson da Silva Constante ${ }^{1}$ \\ Lucas Graeff ${ }^{2}$ \\ Arlete Caye ${ }^{3}$ \\ Anderson Maciel de Andrade ${ }^{4}$
}

\begin{abstract}
"Dirigindo-se à sensibilidade, a fotografia é dotada de uma força de persuasão que aqueles que dela se servem como meio de manipulação exploram conscientemente." Freund (1995: 201).
\end{abstract}

Você já parou para pensar como uma fotografia pode ser paradoxal? Que sentimentos podem surgir quando se está diante de uma imagem, o olhar por ser congelado, você pode fixar-se-a ela por segundos... minutos... horas... Para Samain 2003), a fotografia pode ser comparada a uma múmia, ela pode estar imóvel há anos, enclausurada em sua urna, silenciosa, ou seja muda, ela não mais irá falar, porém no entanto nossa imaginação, mil palavras podem surgir. Neste momento o autor menciona o que podemos classificar de "discursos do silêncio" de uma determinada imagem "Discurso por ela provocados, que surgem dos fundos da nossa interioridade, da caverna obscura de nosso pensamento. Pois, se é verdade que olhamos para ela, também ela olha para nós, nos aponta, nos questiona, nos perscruta, nos desvenda, nos desnuda." (Samain, p. XVIII, in. Achutti, 1997)

Para esse estudo a peça de teatro "Frida Kahlo, à revolução" será o foco. O espetáculo vem sendo apresentado nos palcos, desde 2009, quando foi criado

\footnotetext{
${ }^{1}$ Universidade La Salle, Brasil. Email: robsonconstante80@gmail.com

ORCID id: https://orcid.org/0000-0002-7342-0482

${ }^{2}$ Universidade La Salle, Brasil. Email: lucas.graeff@unilasalle.edu.br

ORCID id: https://orcid.org/0000-0002-5453-525X

${ }^{3}$ Faculdade Anhanguera, Brasil. Email: arletecaye@gmail.com

ORCID id: https://orcid.org/0000-0002-7842-8686

${ }^{4}$ Universidade La Salle e Faculdade Anhanguera, Brasil. Email: andersonandrade777@gmail.com ORCID id: https://orcid.org/0000-0001-7836-9041
} 
conjuntamente a Companhia de teatro, intitulada de Cia Dramática. Quem fica à frente da companhia é quem protagoniza a personagem Frida, a atriz Juçara Gaspar. Seu parceiro e colega de cena, é o músico e ator Luciano Alvez. A peça é dirigida por Daniel Colin.

Juçara Gaspar ao idealizar a peça acabou por também assumir o roteiro do espetáculo, de forma que sempre que narra ou fala de como foi a montagem da personagem, seus olhos brilham e por vezes a emoção vem em forma de lágrimas. Em uma destas falas, a atriz comenta que buscou inspiração por meio de documentários e do filme "Frida" dirigido por Julie Taymor" (2002) em que se baseia na vida da personagem central, porém foi por meio do livro "Releituras de Frida Kahlo - por uma ética estética da diversidade machucada" que o espetáculo foi escrito, no qual faz referência durante a entrevista concedida previamente à equipe de pesquisadores ${ }^{6}$.

A seleção de fotos que compõem este artigo, fizeram parte de uma amostra apresentada na "Mostra fotográfica" do XIX Congresso Brasileiro de Sociologia ${ }^{7}$. O ensaio fotográfico abarcou desde os bastidores, ajustes e marcações do palco, caracterização da atriz e encenação. Os registros selecionados mostram a preparação da atriz no camarim, onde a própria Juçara salienta fazer parte do ritual colocar alguns objetos que a conectam com a personagem, em seguida segue imagens do espetáculo, da entrega da atriz ao papel que interpreta. As imagens foram captadas quando a peça foi encenada no Teatro SESC/RS na cidade de Canoas/RS, dezembro de 2018, tendo um público superior a $80 \%$ de diferentes faixas etárias. A pesquisa foi realizada por meio de observação participante e fotoetnografia (Achutti, 1997). Das imagens selecionadas, pode-se perceber que cada uma delas, carrega em si uma força própria, que transmite tanto a dor como outras emoções que podem ser concebidas com quem as vê despertando empatia com a cena.

\footnotetext{
${ }^{5}$ Filme Frida retrata a vida da pintora mexicana Frida Khalo, estreado em 2002. Uma produção americana e distribuída pela Imagem Filmes.

${ }^{6}$ Nota de esclarecimento: o grupo de pesquisa realizou uma entrevista com atriz da peça de teatro, o qual pode ser acessado por meio do artigo publicado na revista Iluminuras da UFRGS, conforme link: https://seer.ufrgs.br/iluminuras/article/view/90186/51974, intitulado de "O Amor pelo teatro".

${ }^{7}$ A construção da personagem Frida Kahlo: A emoção que transcende do bastidor para o palco. $19^{\circ}$ Congresso Brasileiro de Sociologia - https://sbs2019.sbsociologia.com.br/
} 
Todo esse sofrimento/angústia que fora percebido e que transbordava no semblante da atriz, são absorvidos pelo público que ali estava presente na plateia. A fotografia pode fazer esse papel o de provocar sentimentos de quem a aprecia. Para (Samain: XIX, in. Achutti, 1997) "as fotografias são tecidos, malhas de silêncios e de ruídos, os envelopes que guardam nossos segredos as pequenas peles as películas de nossas vivências, as fotografias são memórias e confidências.".

\section{A Peça Frida Kahlo, à Revolução: uma breve narrativa da sequência das}

\section{fotos}

Ao adentramos no camarim pudemos perceber a concentração da atriz já em transformação com a sua personagem. De fato, percebe-se que não é somente a maquiagem, estilo do penteado, ou a sobrancelha, que fazem desta construção da atriz a personagem, nós estávamos ali no momento de transição e em meio a diversos produtos de maquiagens e acessórios em sua maioria personalizados com imagens da Frida Kahlo. Diante de nossos olhos e ouvidos estávamos envolvidos com o som que vinha da preparação da entonação da voz da personagem que se misturava com a da atriz. Frases soltas do roteiro da peça, e cantarolas de músicas espanholas, eram escutadas, e que puderam ser ouvidas durante a peça, porém neste momento, com o apoio da voz e violão do Luciano o que iria vir a acontecer logo no início do espetáculo.

A entrada da atriz, se dá de forma lenta, chega em sua cadeira de rodas e seu rosto estava tomado pelo sofrimento já entranhado no corpo e alma como a própria Frida. Esta dor poderia vir das lembranças de ter tido amputada sua perna, em decorrência de um acidente sofrido na juventude, e da qual houve diversas sequelas. Uma destas sequelas, a impossibilitou da realização de um dos seus maiores desejos, o sonho de ser mãe, em uma das cenas é narrada a dor e desespero em passar por mais um aborto. Da dor, pudemos presenciar um dos momentos de alegria de Frida, quando ela fazia o que lhe dava prazer, e que de certa forma auxilia a "amenizar" seus sofrimentos (desamores e problemas pessoais), ou seja, a sua profissão como pintora. Sobre um cavalete, havia diversas pinturas, entre elas há um retrato do seu grande amor, amigo e também artista, o Diego Rivera. 
A pintura passa a ser um meio para canalizar todas as emoções que a tomavam, era neste momento que a personagem, consegue transformar toda a sua dor, desilusão, desesperança em arte. Usando de cores vibrantes, acabava por tocar e sensibilizar o espectador. A decrepitude do seu corpo com o passar dos anos são retratados quando a atriz se desnuda e mostra o colete que mantém sua coluna no lugar, como ela, a atriz, declara para o público, sua vida se deve por ter passado por inúmeros profissionais da saúde, e submetidas às mais diferentes tratamentos, entre eles o uso de coletes, a ferros, a amputação de um membro. Contudo a sua paixão pela arte, lhe dava forças para seguir com sua vida.

Para Semain (2003: 50) as imagens evocam emoções, em suas palavras coloca que a "fotografia é uma viagem, melhor ainda: um arrebatamento". Cada um ao apreciar o retrato terá suas próprias impressões, por mais que o contemple, podendo ser o primeiro contato com a fotografia ou revisitando a imagem, haverá mudanças na forma com que a perceberá. Neste sentido compreendemos que a emoção que nos tomou ao selecionar as fotografias, que nos remeteram as memórias vividas ao assistir a peça e despertando a curiosidade para o contexto da peça, nos provoca e leva-nos a ler mais sobre história da artista representada. E é com esse leque de informações que as fotos selecionadas contam uma história particular para cada um que as olhe, criando uma nova impressão a cada vez que se depara com as imagens.

\section{NARRAÇÃO FOTOETNOGRÁFICA:}

Uma das funções da fotografia é nós permitir apreciar o que não se têm tempo quando algo está ocorrendo, mas no ato a captura da imagem, toda a emoção que ali está memorizado, permite ao interlocutor dar-se o tempo que quiser para se sensibilizar, ACHUTTI ( 1997).

Diante da epígrafe acima apresentamos a sequência das fotos da peça teatral: 


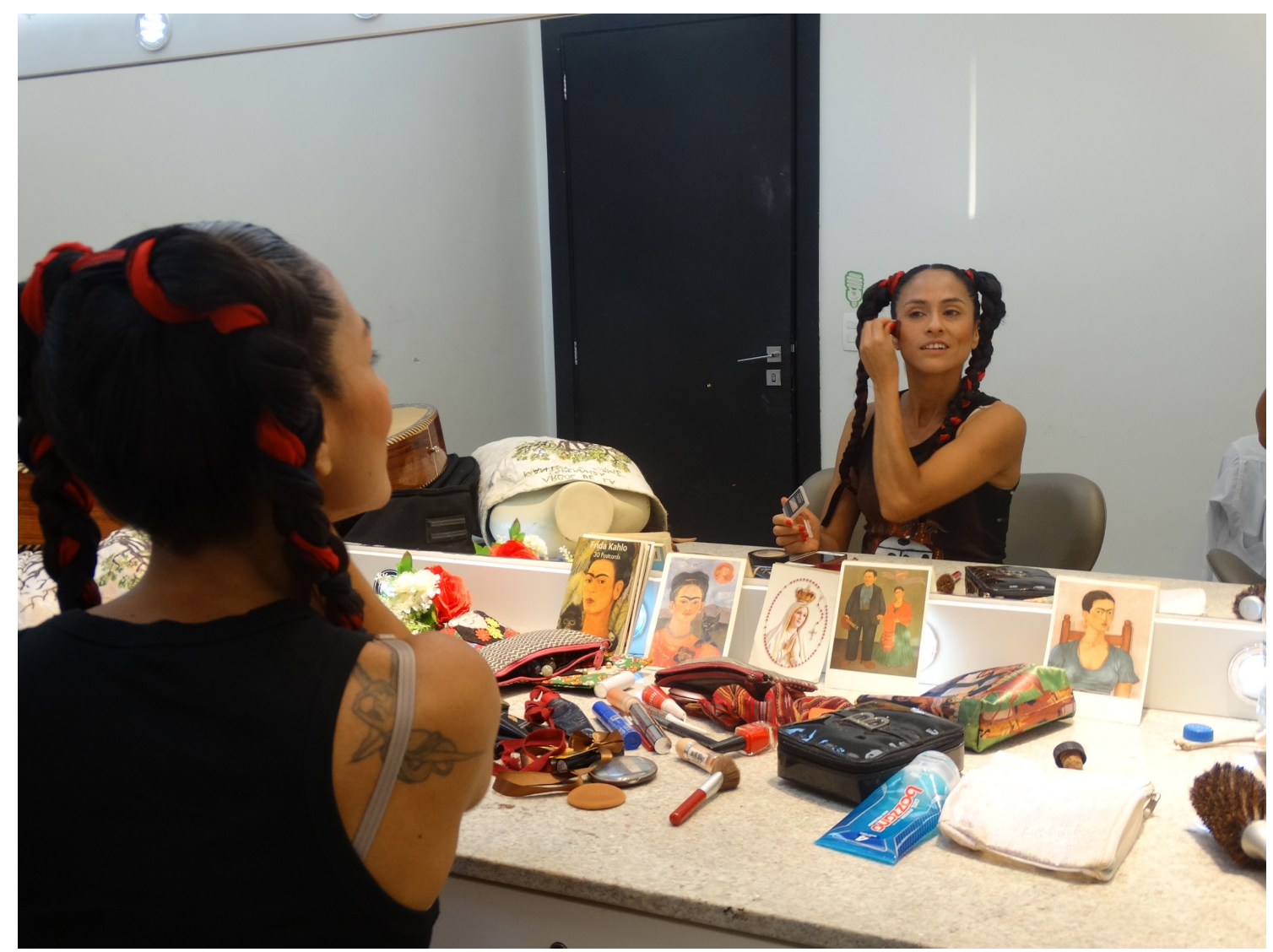




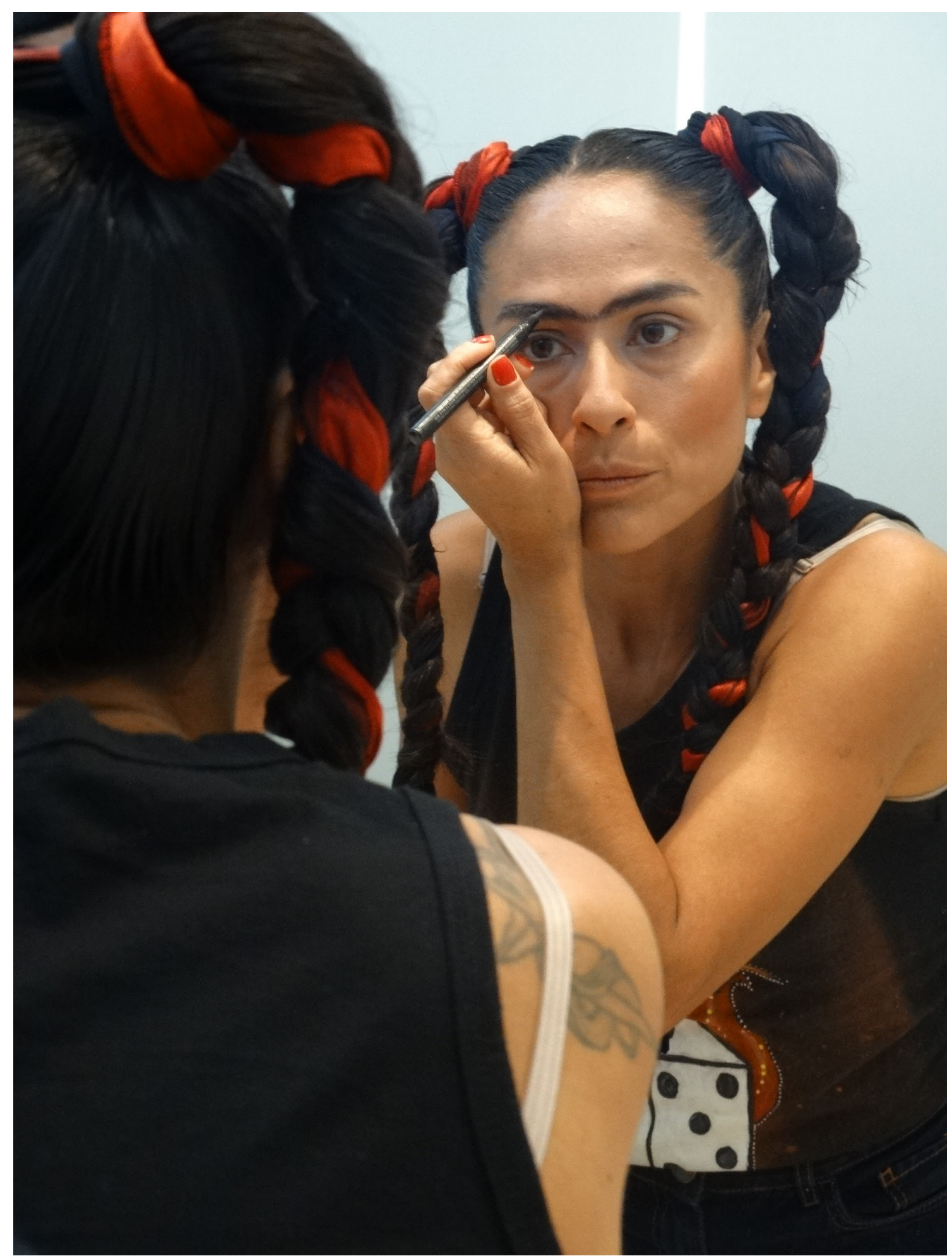



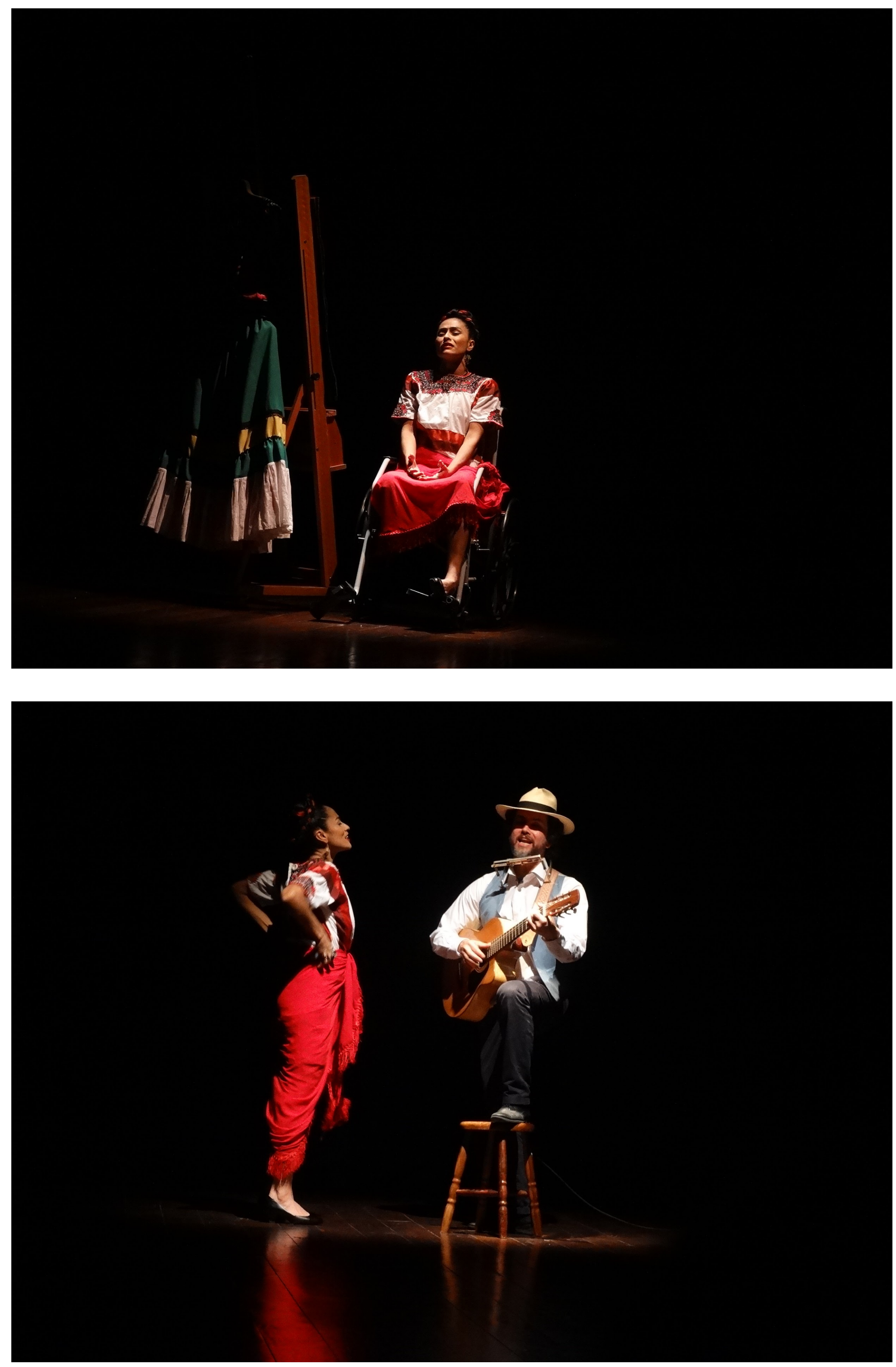


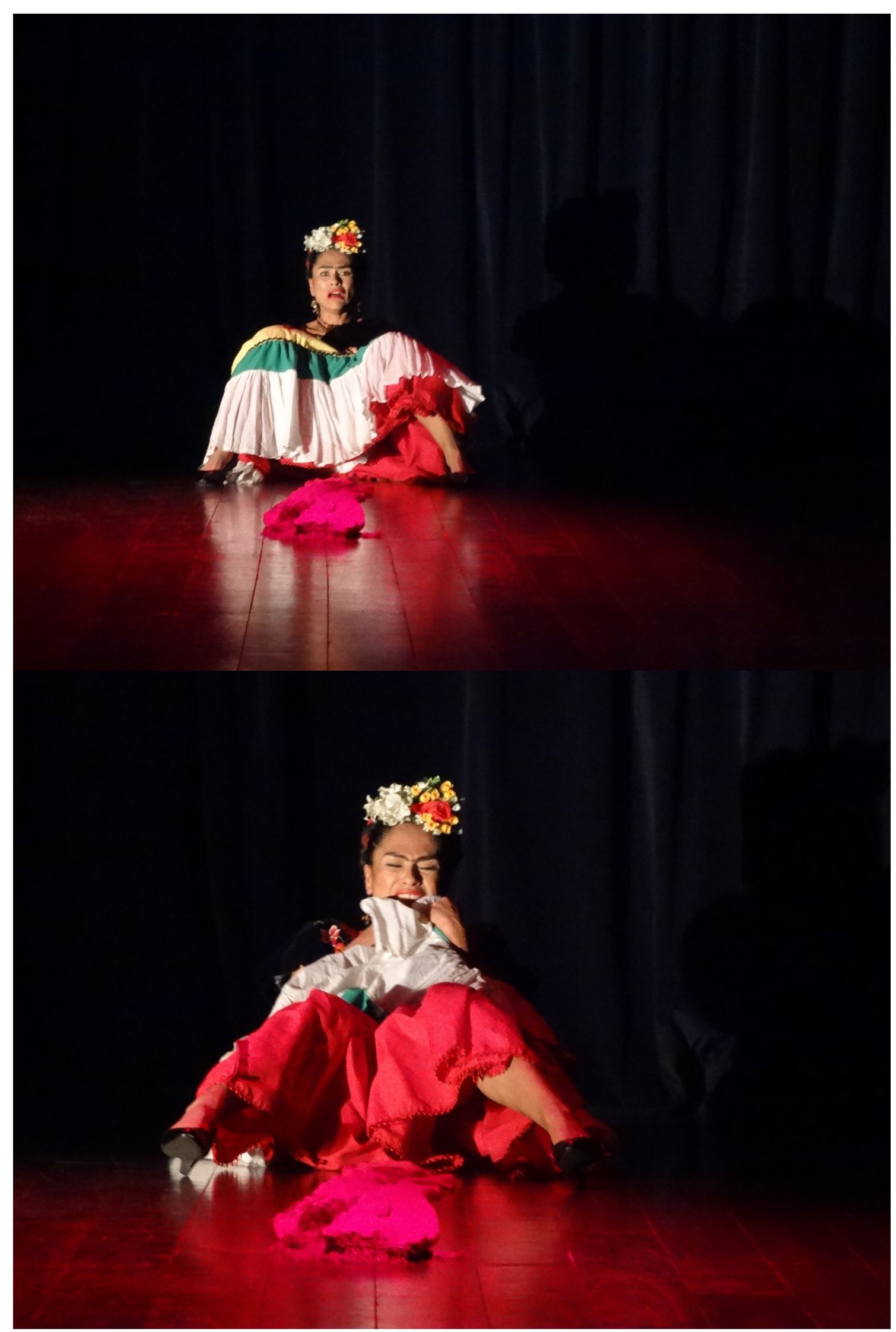




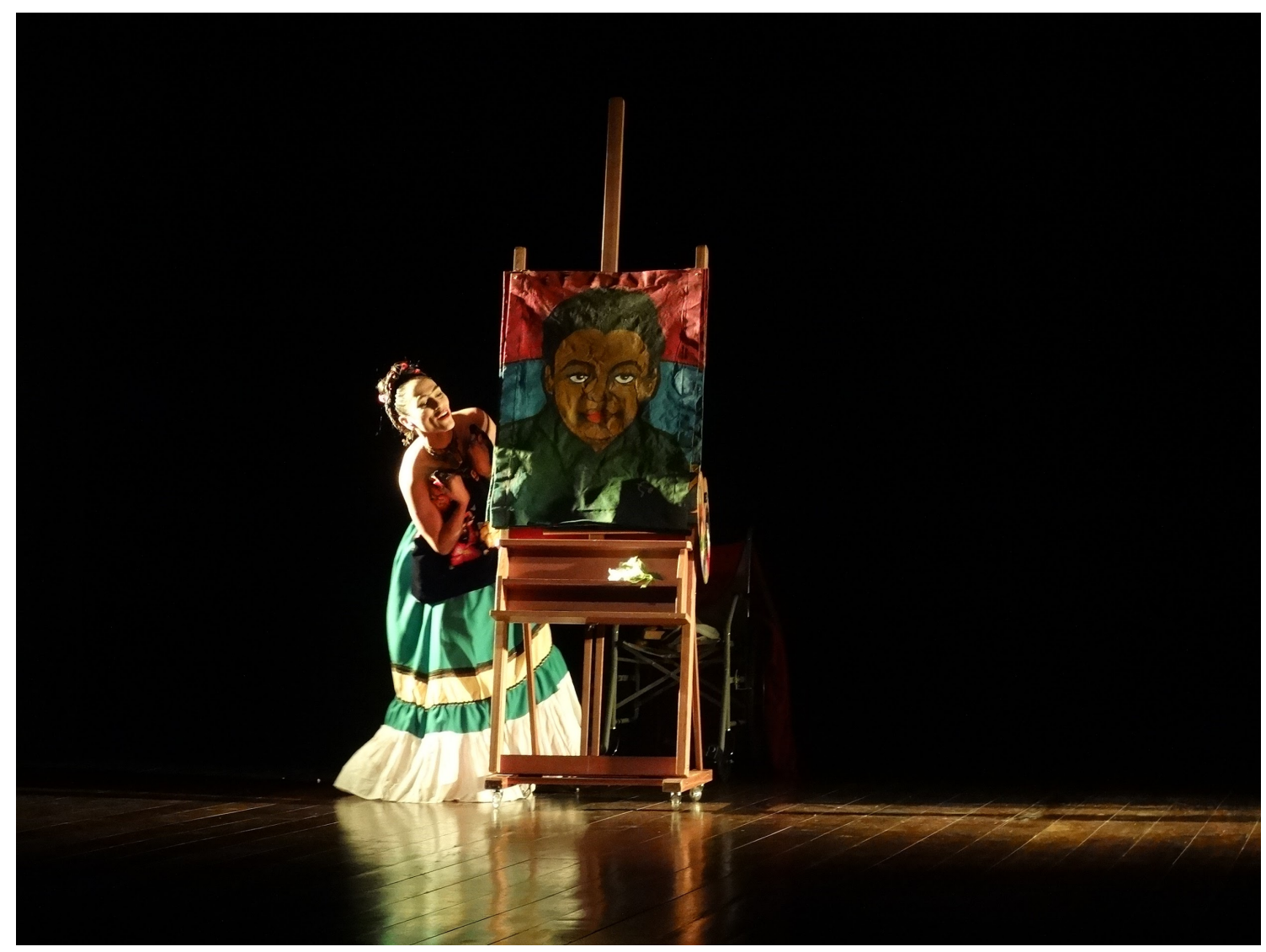




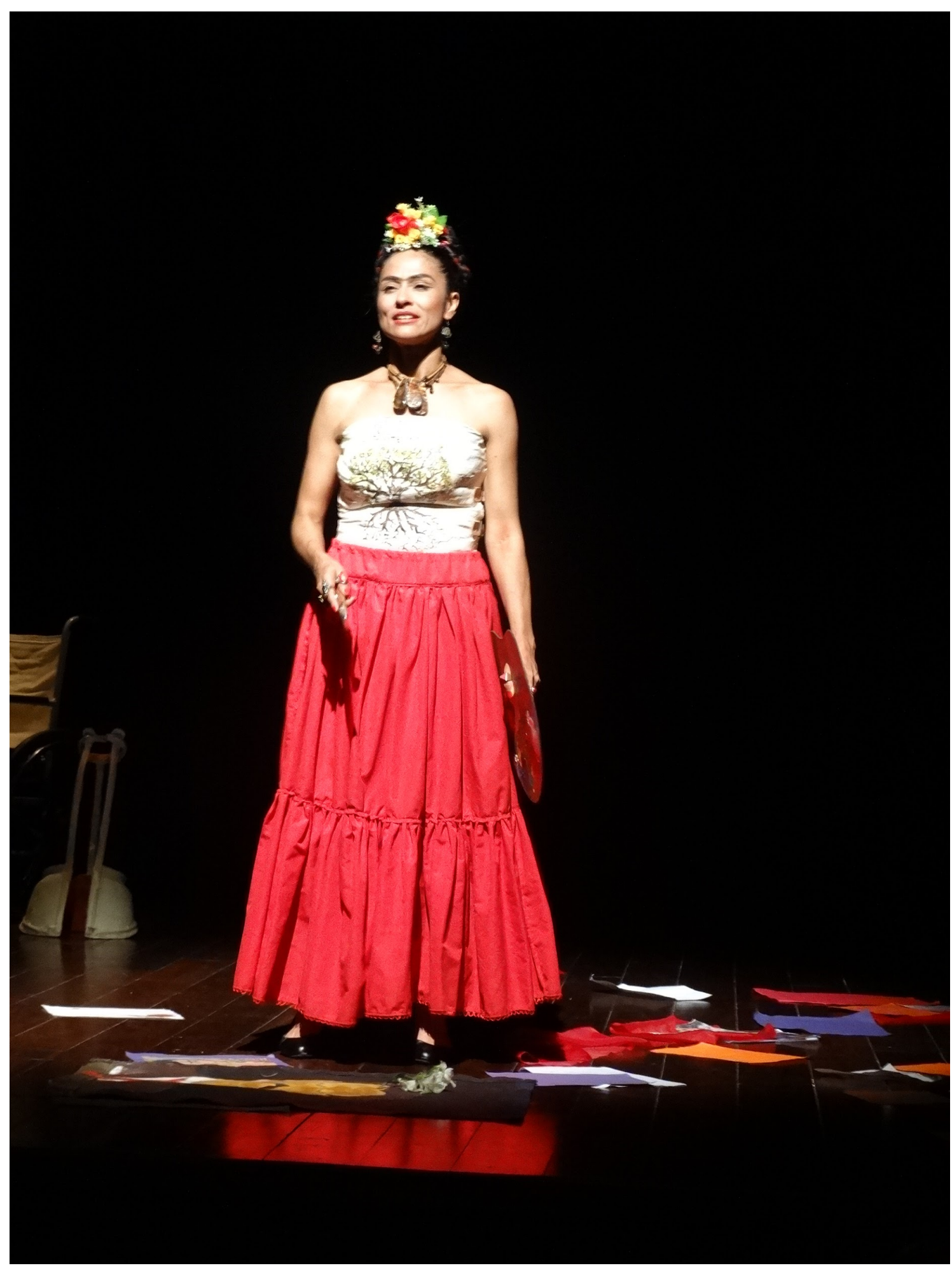









\section{REFERENCIAS}

ACHUTTI, Luiz Eduardo Robinson. Fotoetnografia: um estudo de antropologia visual sobre cotidiano, lixo e trabalho. 1. ed. Porto Alegre, RS: Palmarinca, Tomo, 1997.

FREUND, Gisèle. Fotografia e sociedade. 2. ed. Lisboa: Vega, 1995.

MAY, Tim. Pesquisa social: questões, métodos e processos. 3. ed. Porto Alegre: Artmed, 2004.

SAMAIN, Etienne. Antropologia de uma imagem "sem importância". Ilha. Florianópolis, v.5, n.1, p.47-64, julho de 2003. 